
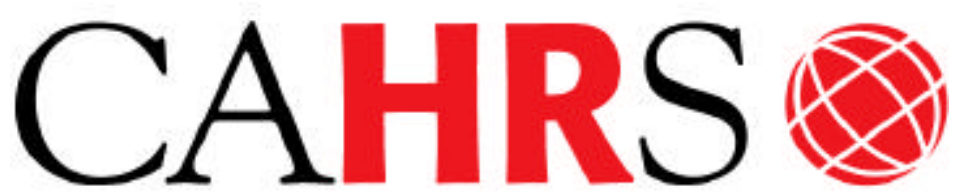

Center for Advanced Human Resource Studies

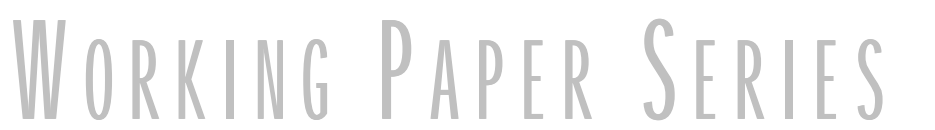

CAHRS / Cornell University 187 Ives Hall

Ithaca, NY 14853-3901 USA

Tel. 607 255-9358

www.ilr.cornell.edu/CAHRS/

\title{
The Role-Based Performance Scale: Validity Analysis of a Theory-Based Measure
}

\section{Theresa M. Welbourne}

Diane E. Johnson

Amir Erez

Working Paper 97 - 05 


\title{
THE ROLE-BASED PERFORMANCE SCALE:
}

\section{VALIDITY ANALYSIS OF A THEORY-BASED MEASURE}

\author{
Theresa M. Welbourne \\ Center for Advanced Human Resource Studies \\ Cornell University \\ 393 Ives Hall \\ Ithaca, NY 14853-3901 \\ FAX: 607/255-1836 \\ Diane E. Johnson \\ University of Alabama \\ Amir Erez \\ University of Florida
}

This study was funded by both the Center for Advanced Human Resource Studies and the Entrepreneurship and Personal Enterprise Program, both at Cornell University. We want to thank Linda Cyr and the members of the Ohio State University Ph.D. seminar for their feedback on earlier versions of this manuscript. In addition, we wish to thank our three anonymous reviewers, and the editor, Greg Northcraft, for their very helpful comments.

All correspondence should be sent to Theresa M. Welbourne 607/255-1139; e-mail: tw19@cornell.edu

http://www.ilr.cornell.edu/CAHRS 


\section{ABSTRACT}

\section{THE ROLE-BASED PERFORMANCE SCALE: VALIDITY ANALYSIS OF A THEORY-BASED MEASURE}

This study introduces a theory-based measure of employee performance (Role Based Performance Scale, RBPS) that is supported with results from a validation study using 10 data sets from six companies. In contrast to traditional, job-related measures of employee performance, we propose an alternative measure of performance based on role theory and identity theory. Because our results support the validity of the scale, we think that the instrument can be used for future research that requires a generalizable measure of performance. The scale demonstrates diagnostic properties that make it useful for practitioners as well as researchers. 


\section{INTRODUCTION}

To gain competitive advantage in a global economy, organizations have instituted programs such as total quality management, employee involvement, job enrichment, skill-based pay, autonomous work teams, and gainsharing plans (Lawler, 1992; Lawler, Mohrman, \& Ledford, 1992). The goal of these and many other interventions is to increase firm performance by affecting employee behavior on the job. Although each takes a different approach, all of these initiatives are designed to encourage employees to change the way they work, take on increasing responsibility, and actively contribute to the accomplishment of group-based and organizational objectives (Lawler, 1986). The result is that employees do much more than what is traditionally included in their job descriptions. Despite these significant organizational changes, only recently have researchers started altering the prevailing view of what constitutes individual performance (Borman \& Motowidlo, 1993).

According to Bommer, Johnson, Rich, Podsakoff, and MacKenzie, "Job performance is the most widely studied criterion variable in the organizational behavior and human resource management literatures" (1995: 587). However, most performance measurement systems are limited in that they ignore dimensions of work behavior that lie beyond what has been traditionally included in the scope of a specific job itself. This is not surprising because recommendations for creating a legally defensible performance appraisal system tend to require a formal job analysis (Bernardin, Kane, Ross, Spina \& Johnson, 1995). Job analysis, by design, ignores non-job related behaviors. However, excluding non-job dimensions creates problems for firms that intend to reward behaviors such as suggestion making, organizational citizenship, or even extraordinary customer service.

Performance appraisal systems have evolved over the last 60 years. One can characterize the change as a movement from an early emphasis on the person, to a sophisticated focus on the job, with a recent return to the person (Milkovich \& Boudreau, 1997). Early performance appraisal was fairly simplistic and involved rankings and comparisons of individuals with other people (e.g. simple ranking methods). However, these early person-based measurement systems often exhibited a number of problems (see review of error research in Cardy \& Dobbins, 1994). As a result, researchers made a transition to job-related performance assessments. These resulted in a need for accurate descriptions of jobs and an understanding of the performance appraisal process. Sophisticated models for understanding performance appraisal, some that elaborated upon the underlying cognitive process, have been developed and tested throughout the past 30 years (see Cardy \& Dobbins, 1994; Murphy \& Cleveland, 
1995 for reviews of this work). Thus, performance measurement was modified from being person oriented to being behaviorally oriented, with the emphasis being on those tasks or behaviors that were associated with the job.

Recently, both practitioners and academics have realized that an emphasis on the job, per se, may lead to the omission of other important components of overall performance. According to Milkovich and Boudreau (1997: 87), "organizations are replacing the notion of 'jobs' with considering what 'roles' or 'competencies' will be required for the $21^{\text {st }}$ century." This trend has led to a renewed interest in the 'person.' In particular, organizations have begun to develop appraisal systems based on competency models, which focus on the skills needed to be effective in one's current and future job (Lawler, 1994). Even though the emphasis is returning to the person (vs. the job), competency models continue to be defined by job attributes. For example, Mansfield (1996: 7) defines a competency model as "a detailed, behaviorally specific description of the skills and traits that employees need to be effective in a job." This continued job orientation may result from the need to meet legal requirements, but we think the result is a narrow view of overall employee performance.

During the last decade, several researchers have attempted to call attention to the importance of non-job components of performance (Austin \& Villanova, 1992). For example, Bateman and Organ (1983) introduced the notion of organizational citizenship behavior (OCB), which represents voluntary employee actions that benefit the employer but are not required. These authors and others suggested that work performance is two-dimensional, composed of work required by the organization as well as discretionary employee work behaviors (Van Dyne \& LePine, 1998). Expanding this two-dimensional model, Motowidlo and colleagues recognized the importance of non-task performance, which they called contextual performance (Borman and Motowidlo, 1993; Borman \& Motowidlo, 1997; Motowidlo, Borman, \& Schmit, 1997; Motowidlo \& Van Scotter, 1994). These authors suggested that contextual performance itself consists of multiple "subdimensions" such as teamwork, allegiance, and determination. Campbell and colleagues (Campbell, 1990; Campbell, McCloy, Oppler, \& Sager, 1993) also expanded this two-dimensional concept of work roles by presenting an eight-factor model of work performance that includes job specific and non-job behaviors.

Although multidimensional models of performance that include job and non-job dimensions have been introduced, they lack a unifying theoretical framework (Borman \& Motowidlo, 1993, Campbell, 1990; Borman \& Motowidlo, 1997; Motowidlo \& Van Scotter, 1994). Without a theoretical underpinning, there is little guidance for choosing which dimensions of performance (job or non-job) to include or exclude from a model. Thus, researchers and 
organizations tend to use customized performance measures, which results in utilizing measures that do not typically allow for comparisons among jobs or across companies. Many researchers have noted that this lack of generalizability of the performance criterion hinders the validity of many predictors of performance (Austin \& Villanova, 1992).

We use role theory and identity theory to develop a theory-based, generalizable measure of performance. Role theory provides an explanation for why work performance should be multidimensional, and identity theory suggests how to determine which dimensions to include in a model of work performance. By utilizing these two theories, we suggest a measure of performance that includes five different roles (job, career, innovator, team member, and organization citizen). After introducing the conceptual model, we report the results of the validation study.

\section{ROLE THEORY, IDENTITY THEORY, AND PERFORMANCE MEASUREMENT}

The following section applies both role and identity theory to the topic of performance measurement. By doing so we introduce a set of roles that we suggest should be measured in an instrument that focuses on measuring overall performance at work.

\section{$\underline{\text { Role Theory }}$}

Role theory has been used effectively by researchers in psychology, social psychology, sociology, organization behavior, and human resource management since the early 1930s. Multiple researchers from these various fields have concluded that roles play an important part in social structure (Mead, 1934; Turner, 1978), and roles have been recognized as central to understanding employee behavior in organizations (Katz \& Kahn, 1978). In the strictest sense, roles are positions within a social framework (Oeser \& Harary, 1964); however, they also are defined by the individuals who occupy them (Callero, Howard, \& Piliavin, 1987; Oeser \& Harary, 1964). According to role theory, individuals' role expectations are influenced by both their personal attributes and the context in which they exist. Thus, role theory suggests that employee performance will be a function of both the individual and the organization. This theory represents a major advancement in explanations for performance since it combines both a psychological (individual contributions) as well as sociological (organizational framework) perspective. Previous attempts to theoretically explain performance have sought either individual predictors or environmental predictors, neglecting to recognize that both can contribute simultaneously. 
An important contribution of role theory to performance management is its ability to provide direction for how to avoid measurement errors in performance appraisal tools. Although not using role theory specifically, researchers have suggested using roles as the basis for job descriptions as well as for specifying organizational expectations and performance requirements (Ilgen \& Hollenbeck, 1992; Van Dyne, Cummings, \& Parks, 1995). Despite this recognition of the importance of roles, and the fact that employees choose to enact multiple roles in the organization, research has continued to measure employee performance as if only one role (the job holder) exists.

As a result, performance systems that rely on evaluating only those work behaviors defined by the organization as related to a specific job may exhibit deficiency error. In order to correct for this measurement error, role theory suggests that performance management systems need to account for multiple roles at work. In fact, recently, researchers have begun to recognize the importance of using roles as a way to conceptualize work performance (Ilgen \& Hollenbeck, 1992; Jackson \& Schuler, 1995). Ilgen \& Hollenbeck (1992) offer a theoretically-based model of work roles, which provides a major contribution to viewing work performance from this perspective. These authors provide a comprehensive argument for the need to incorporate roles in a theory of work performance. Their main claim is that the omission of roles, in any approach to performance, is deficient (see llgen \& Hollenbeck, 1992, for review).

While we concur, we also argue that role theory only suggests roles as a way to conceptualize multiple behaviors at work; it does not provide a way to define which dimensions of performance (or roles) should be included or excluded in a multidimensional measure of performance. The number of potential roles employees may take on at work is limitless. One theory that may help in understanding which roles should be measured in an instrument that focuses on behavior at work is identity theory.

\section{Identity Theory}

According to identity theory, it is not the existence of roles, but their saliency, which affects behavior (Burke, 1991; Thoits, 1992). Identity theory suggests a process by which people use an internal control system to filter information. The likelihood that an event or information will trigger behavior, is associated with the saliency of a particular role (Thoits, 1991; 1992). According to Thoits "the more salient the role identity, the more meaning, purpose and behavioral guidance the individual should derive from its enactment (1991: 106)." In other words, those roles which are most salient to us provide us with the strongest meaning or purpose. In turn, the more meaning we derive from a role, the greater the behavioral guidance 
that ultimately leads to the enactment of behaviors associated with that role. Thus, organizations can affect behavior of employees at work by influencing the saliency of work-related roles. Firms influence work-related role saliency in many different ways including rewarding behaviors, requiring behaviors, formal and informal recognition, and even punishment when behaviors are not enacted. Since different organizations have different expectations of their employees, role saliency is most likely to be different across organizations. Because firms differ in the roles they consider important for individual success, it has been difficult to create a generalizable performance measure applicable to all firms.

While all of the ways by which organizations influence role saliency should be explored to determine which roles are most appropriate to include in a performance measure, a project of this size is beyond the scope of this paper. In an effort to begin the process of discovery, we employed two additional criteria. First, we chose one obvious method employed by firms to encourage certain work roles. Specifically, we chose to review several compensation systems and the roles they are designed to elicit. While this analysis is not all-inclusive, it provides an exploratory foundation for establishing a basic role-based performance measure. Second, we chose roles that have been emphasized by other researchers as important for organizational success. Combined with role theory and identity theory, these two criteria provided us with five unique roles: job, organization, team, career, and innovator.

In sum, we suggest that employees enact multiple roles beyond just "the job" (role theory), and by employing identity theory, we suggest that those roles that are considered important from the organization's perspective should be measured in a comprehensive assessment of employee performance. Compensation systems are one of the tools used by organizations to communicate their intentions. Therefore, compensation systems provide a 'clue' for uncovering which roles should be measured at work because they are one of the mechanisms by which firms communicate which particular roles are considered important for the firm's success. Combined with researchers' recommendations, we developed the Role-Based Performance Scale (RBPS).

\section{Roles included in the RBPS}

Based upon previous models of performance, the job and organization roles are easily identifiable as dimensions of work performance. The job holder role represents the traditionally held view of employee performance, whereas the organization member role parallels those behaviors associated with organizational citizenship behaviors (Organ, 1988). While the job role is clearly the most heavily researched over the last 60 years (Austin \& Villanova, 1992), 
numerous studies have investigated, more recently, the importance of organizational or non required work roles (Bateman \& Organ, 1983; Borman \& Motowidlo, 1993); Brief \& Motowidlo, 1986; Borman \& Motowidlo, 1997; Motowidlo \& Van Scotter, 1994). Both roles have been demonstrated to be enacted by employees in the work place. Moreover, the job role is clearly supported by compensation systems (e.g. merit pay, individual bonus plans).

Welbourne and Cable (1995) recently applied identity theory to the study of group-based incentives. Their research only considered the job holder role and the organization member role. Whereas Welbourne and Cable (1995) found that the saliency of the job holder role was affected by the implementation of individually-based incentive systems (such as merit pay, sales commission, or piece rate plans), the organization member role was influenced by the existence of group-based incentive plans (such as profit sharing, gainsharing, goal sharing and stock options or grants). These initial findings provide evidence that different types of rewards affect the saliency of different roles enacted at work.

Expanding on this same logic, varying forms of compensation may encourage other types of role-related behavior at work. In addition to the job holder and organization member roles, we have identified three other key roles. These other roles were identified by reviewing the work of several authors who emphasized their importance (e.g. Gerhart, Minkoff \& Olsen, 1995; Milkovich \& Newman, 1990).

In addition to the job and organizational member role, we suggest that there is a career role. Promotion systems reward individuals for career accomplishment (Noe, Hollenbeck, Gerhart \& Wright, 1994). Another pay system that emphasizes the career role is skill-based pay (Ledford, 1991). These pay programs provide employees with increases in their base pay when they participate in training and acquire new skills. Career roles, however, should be considered in performance models for another important reason. It is commonly accepted that a new psychological contract is developing between employees and employers in which both share responsibility for career planning (Miner, 1986). Many would argue that companies no longer can offer job security and promotion opportunities. As a result, the new psychological contract implies employers provide a well-developed career program while employees should attempt to increase their value to employers by taking responsibility for career planning (Noe, et al., 1994). Thus, employers can emphasize the importance of career roles either directly through compensation plans or by providing career development opportunities for employees. This increased recognition of and emphasis on joint career responsibility between employers and employees makes the career role an important role to consider in a model of performance. 
The second additional work role identified is that of team member. Arguably, teamwork has been a critical component of organizational performance for years; however, recognition of the importance of the team member role as well as the use of teams in organizations has increased only over the last several years (Stevens \& Campion, 1994). In fact, many of the new performance models have included teamwork as a vital component (Borman \& Motowidlo, 1997; Campbell, 1990). In addition, the compensation literature clearly provides evidence of the increasing reliance on teams in organization. Gainsharing plans and team-based incentives both support behaviors associated with the role of being a team member. We noted earlier that gainsharing plans (which share business unit financial performance gains with the entire workforce) reward behaviors associated with the organizational member role (Welbourne \& Cable, 1995). These pay systems also encourage cooperation among team members and between teams (Welbourne \& Gomez-Mejia, 1995).

The fifth and final role included in our model of performance is that of innovator. Schein (1980) argued that if firms intend to remain competitive in a complex and changing environment, they must have employees who are creative on behalf of the entire organization, not just creative in one's job. This implies that employees need to behave in an innovative way, beyond the traditional sense where jobs require product development skills, and perform innovator "roles" which contribute to the effectiveness and adaptability of the organization as a whole (Shein, 1970; 1980; Van Maanen \& Schein, 1979). Many companies provide compensation incentives, such as gainsharing and cash rewards for suggestions, which promote this entrepreneurial type role. Moreover, the innovator role is important in both large and smaller organizations (Gomez-Mejia \& Balkin, 1992). This final role expands employee work performance to include five different roles: job holder, organization member, career role, team member, and innovator.

As discussed earlier, there are many potential roles that employees can enact while at work. Thus, we are not suggesting that the five roles outlined in the RBPS are the only relevant roles; however, these five roles clearly have theoretical support for their inclusion in a performance measure. We suggest that these roles are indeed unique from each other and that they measure components of performance that are not necessarily obtained via a firm's traditional performance appraisal system. Thus, we propose the following hypotheses:

Hypothesis 1: The five roles assessed in the RBPS (job holder, organization member, career, innovator, and team member) measure components of behavior that, while related to each other, are unique. 
Hypothesis 2: The five roles suggested in the RBPS measure components of behavior above and beyond what is assessed in a company's traditional performance appraisal instruments.

Although we used compensation systems to provide a 'clue' about which roles should be included in our measure, this study was not designed to test whether or not organizations are successful in eliciting these roles using the different compensation systems. Rather, we are interested in the validity of the RBPS and its contribution to predicting dimension of performance above what can be obtained with traditional performance appraisal measures. If the RBPS is shown to make a valid contribution to explaining overall performance at work, future research may benefit by using this measure as a diagnostic tool for investigating a firm's ability to elicit specific roles using different compensation methods.

This research project was conducted in several stages using multiple samples. Stage I was the development of the RBPS. We examined the dimensionality of the scale, and we also explored its face validity and practicality. In stage 2, we focused on the psychometric properties of the scale by assessing the reliability of the scale and the distinctness of its dimensions (testing hypothesis 1). Finally, in stage 3, we examine the construct validity of the role-based performance scale by determining whether the RBPS can predict organizational outcomes above and beyond what is obtained with a firm's traditional performance appraisal system (tests of hypothesis 2). In addition, these analyses address whether or not the RBPS reduces deficiency error typically associated with traditional performance measures that only focus on the job role.

\section{METHODS}

\section{Samples}

The data were collected from employees and managers at six different companies. Data were obtained from employee self evaluations in all the organizations and from managers' evaluations of subordinates in 3 of the organizations. In addition, we obtained data from the personnel files at several of the participating firms. The data included age, gender, current salary, most recent salary increase, and most recent performance appraisal score. The archival data varied by firm. The firms ranged from a large, unionized plant in a Fortune 100 company to a small, start-up software firm. The companies were in various industries, including traditional manufacturing, service, and high-technology. The employees held jobs in various areas of their companies including management, engineering, sales, marketing, manufacturing, administration, computer programming, and customer service. 
The site of the pilot test, located in the western United States, was a division of a large, multinational manufacturing firm. A stratified, random sample of 90 employees was selected from the total employee population of approximately 700 . Most of the employees were unionized and in manufacturing positions, but the sample included non-union employees and managers. Only the managers of non-union employees completed the evaluations of performance.

Five additional companies participated in the second stage of the study. The first company, company A, was a fast-growing, software firm located in the western United States. The second firm, company B, was a small, recently acquired division of a Fortune 100 organization. Employees in this company provided customized brokerage services, and their positions were primarily administrative. Company $\mathrm{C}$, a manufacturing plant, was part of a Fortune 100 company. This group consisted of employees doing fairly traditional assembly-type work. The fourth firm, company D, was a small department of a Fortune 100 organization. The employees performed creative work (design) and sales. The last firm, company E, was a small entrepreneurial software firm experiencing slow, but steady, growth.

\section{Stage 1: Item Development and Pilot Test}

The items included in the Role-Based Performance Scale were originally developed for use in a multi-company study of group-based compensation systems. The study originally involved ten Fortune 100 firms (although all were involved in the original meetings, not all firms participated in the data collection part of the study). At least one human resource representative from each firm participated in an initial meeting about the research project. Participants were provided information about different compensation systems (e.g. gainsharing, skill-based pay) as well as role information and asked to describe what roles they required in their organization as applied to the different compensation systems. This information, combined with some of the literature and measures commonly used (e.g. team, organizational citizenship behaviors) on different roles, was then reduced to a manageable survey by the researchers. Once the items were written, the human resource managers reviewed the survey and asked other managers in their firms to read and critique it. All were asked to evaluate the individual survey items based on their readability, applicability to the organization, ease of understanding, and whether or not these behaviors actually reflected roles in the firm. In this way, we also pilot-tested the usefulness of the survey.

The performance measure had to be easy to complete as in most cases one manager had to evaluate several employees. In addition, we were seeking high face validity; managers needed to believe that their time was being well spent. After narrowing the list of items down to 
four items per role and rewording items on the basis of feedback from the human resource managers, we pilot-tested the survey items. One of the participating firms volunteered a manufacturing site for the pilot test. Because the number of manager evaluations was small (we obtained data from only managers of non-union employees, $\mathrm{N}=21$ ), only the self-ratings were used for the analysis.

In addition, we met with the managers of the union employees to discuss their reactions to the items.

Employees completed surveys in small group meetings at the company site. Two researchers held ten meetings over the course of two days so that employees from all shifts and departments could be included in the study. Researchers allowed employees to ask questions while completing the questionnaire and to make notes on their surveys if they had questions or comments about particular items. Following survey completion, the researchers led discussions to elicit feedback and comments. An exploratory factor analysis was conducted for the selfevaluation survey data. The factor analysis with varimax rotation resulted in a five-factor solution. The eigenvalues were 8.05 for the innovator role, 2.98 for career person, 1.94 for team member, 1.37 for organization member, and 1.07 for job holders. Coefficient alphas for each of the factors were as follows: job $=.76$; innovator $=.90$, career $=.88$; team $=.87$, and organization $=.87$. The items used for each factor can be found in Appendix A.

All but two items loaded on the hypothesized factors. One exception was the item "customer service," which we predicted should be classified under the job role, but which actually loaded with the innovator role. In addition, one item from the organization member category, "Doing things to help others, even when it's not part of my job," loaded with the team member items. Our discussions with managers suggested that at this particular company, employees did not interact with customers, so customer service was not emphasized as part of their job role. However, part of employees' team role was to help coworkers. Thus, in view of the exploratory factor analysis and our follow-up interviews with employees and managers, we decided to retain all survey items, as originally designed, for subsequent studies.

\section{Stage 2: Psychometric Properties and Distinctiveness of the Five Roles}

The purpose of this stage of the study was to contribute toward understanding the construct validity of the RBPS. Several major indicators of construct validity were explored. We investigated the reliability of the scale, its distributional properties, and the dimensions' 
discriminant validity. Table 1 presents means, standard deviations, correlations, and sample sizes for employee data sets at all companies ${ }^{1}$.

\section{Reliability Estimates}

Coefficient alphas were calculated in order to examine the reliability of the RBPS. Table 1 provides the results of this analysis. Across all ten data sets and five variables, all alpha values were equal to or greater than .71, with two exceptions. For the company B employees, the alpha for the job factor was .67, and for the company D employees, the alpha for the job factor was .59. All other values ranged from .71 to a high of .94. The average alpha value for each of the five factors is as follows: job holder $=.75$; innovator $=.90$; career person $=.90$; team member $=.87$; and organization members $=.84$. Since each factor consists of only 4 items, these reliability estimates represent exceptionally strong internal consistency. For the entire scale (all 20 items), alpha values ranged from .86 to .96 among the ten samples. The strength of these reliability estimates suggest a high homogeneity among the scale items.

\footnotetext{
${ }^{1}$ Correlations for other samples exhibit similar patterns.
} 
TABLE 1

Means, Standard Deviations, Correlations and Sample Sizes

\begin{tabular}{|c|c|c|c|c|c|c|c|c|}
\hline & & & & \multicolumn{5}{|c|}{ Correlations } \\
\hline & Means & S.D. & $\mathrm{N}$ & 1 & 2 & 3 & 4 & 5 \\
\hline \multicolumn{3}{|c|}{ Company A (Employees) } & 141 & & & & & \\
\hline Job & 16.91 & 1.85 & & $(.71)$ & & & & \\
\hline Innovator & 14.40 & 2.82 & & .41 & $(.88)$ & & & \\
\hline Career & 12.33 & 3.55 & & .14 & .38 & $(.92)$ & & \\
\hline Team & 16.21 & 2.17 & & .43 & .37 & .26 & $(.77)$ & \\
\hline Organization & 15.54 & 2.39 & & .44 & .43 & .18 & .58 & $(82)$ \\
\hline \multicolumn{3}{|c|}{ Company B (Employees-Incentive) } & 100 & & & & & \\
\hline Job & 17.17 & 2.00 & & $(.67)$ & & & & \\
\hline Innovator & 14.75 & 3.06 & & .31 & $(.90)$ & & & \\
\hline Career & 12.72 & 3.73 & & .31 & .43 & $(.89)$ & & \\
\hline Team & 16.22 & 2.48 & & .36 & .23 & .42 & $(.85)$ & \\
\hline Organization & 16.44 & 2.41 & & .33 & .35 & .47 & .59 & $(.79)$ \\
\hline \multicolumn{3}{|c|}{ Company C (Employees) } & 226 & & & & & \\
\hline Job & 17.05 & 2.81 & & $(.87)$ & & & & \\
\hline Innovator & 15.02 & 3.36 & & .47 & $(.91)$ & & & \\
\hline Career & 14.23 & 3.9 & & .30 & .52 & $(.92)$ & & \\
\hline Team & 15.71 & 2.97 & & .49 & .57 & .49 & $(.86)$ & \\
\hline Organization & 16.19 & 2.82 & & .38 & .47 & .47 & .65 & $(.84)$ \\
\hline \multicolumn{3}{|c|}{ Company D (Employees) } & 89 & & & & & \\
\hline Job & 16.98 & 1.84 & & $(.59)$ & & & & \\
\hline Innovator & 15.05 & 2.92 & & .28 & $(.87)$ & & & \\
\hline Career & 11.67 & 3.10 & & .31 & .29 & $(.83)$ & & \\
\hline Team & 16.26 & 2.62 & & 27 & .40 & .14 & $(.86)$ & \\
\hline Organization & 15.42 & 2.81 & & .31 & .20 & .11 & .56 & $(.81)$ \\
\hline \multicolumn{3}{|c|}{ Company E (Employees) } & 97 & & & & & \\
\hline Job & 17.13 & 2.04 & & $(.71)$ & & & & \\
\hline Innovator & 14.79 & 2.76 & & .31 & $(.88)$ & & & \\
\hline Career & 11.47 & 3.73 & & .13 & .42 & (.91) & & \\
\hline Team & 16.38 & 2.54 & & .18 & .22 & .30 & $(.87)$ & \\
\hline Organization & 16.23 & 2.20 & & .15 & .25 & .29 & .40 & $(.72)$ \\
\hline
\end{tabular}

Reliabilities in parentheses; S.D. = standard deviation; $\mathrm{N}$ sample size

All correlations above .17, $\mathrm{p} \leq .05$, one-tailed tests; all correlations above $.25, p \leq .01$, one-tailed tests; all correlations above .31, $\mathrm{p} \leq .001$, one-tailed tests

Note: Tables for other samples are available from the authors. 


\section{Discriminant Validity}

We conducted confirmatory factor analysis procedures to explore the discriminant validity of the RBPS dimensions. Using LISREL 8 (Jöreskog, \& Sörbom, 1993), seven models, associated with different hypothesized factors were developed, and the constructs were represented as latent variables with items as indicators of each latent variable. The most restrictive model (the null model) consisted of 20 orthogonal factors that corresponded to the 20 -item scale. The second model allowed the 20 measured items to load on one factor. The third model featured our five hypothesized factors -- job, team, organizational, innovator, and career-- in which the four items associated with its respective factor, were allowed to load on that factors. If the five constructs are distinct, (as hypothesized), the third model should produce the best fit.

We also developed four alternative models to explore the possibility that some of the dimensions were not really distinct. We were particularly interested in the job factor because it is the main construct of interest in most work situations. The job dimension should always be part of a performance scale; however, a failure to distinguish the job dimension from another performance dimension may indicate that the additional dimension is repetitive and should be eliminated. Thus, in the four alternative models we loaded the indicators of three of the four additional dimensions on their hypothesized constructs while the indicators of job and the indicators of one of the additional dimensions were loaded on one factor. Accordingly, in model 4 , items associated with the job role were loaded with team member; in model 5 , job was loaded with organization member; in model 6 , job was loaded with innovator; and in model 7, job was loaded with the career role. All samples were analyzed and results were similar among the data sets. Table 2 reports data for companies A (both manager and employee samples), B, C, D, and E. 
TABLE2

Fit Statistics of Confirmatory Factor Analyses in Stage 2

\begin{tabular}{|c|c|c|c|c|c|c|}
\hline Model & df & Chi-square & GFI & AGFI & CFI & IFI \\
\hline \multicolumn{7}{|l|}{ Company A Managers $(\mathrm{N}=80)$} \\
\hline 1. Null ( 20 orthogonal factors) & 190 & 1817.28 & .15 & .06 & --- & --- \\
\hline 2. One factor & 170 & 814.99 & .44 & .31 & .60 & .61 \\
\hline 3. Five factors & 160 & 345.42 & .71 & .62 & .89 & .89 \\
\hline \multicolumn{7}{|l|}{ Company A Employees $(N=141)$} \\
\hline 1. Null ( 20 orthogonal factors) & 190 & 1717.01 & .33 & .25 & --- & --- \\
\hline 2. One factor & 170 & 1029.42 & .53 & .42 & .56 & .44 \\
\hline 3. Five factors & 160 & 315.06 & .82 & .76 & .90 & .90 \\
\hline \multicolumn{7}{|c|}{ Company B Employees-Incentive $(N=100)$} \\
\hline 1. Null ( 20 orthogonal factors) & 190 & 1231.19 & .31 & .24 & --- & --- \\
\hline 2. One factor & 170 & 699.88 & .54 & .43 & .49 & .50 \\
\hline 3. Five factors & 160 & 245.09 & .82 & .76 & .92 & .92 \\
\hline \multicolumn{7}{|l|}{ Company C Employees $(N=226)$} \\
\hline 1. Null ( 20 orthogonal factors) & 190 & 3431.33 & .22 & .14 & --- & --- \\
\hline 2. One factor & 170 & 1621.38 & .52 & .41 & .55 & .55 \\
\hline 3. Five factors & 160 & 397.71 & .86 & .82 & .93 & .93 \\
\hline \multicolumn{7}{|l|}{ Company D Employees $(\mathrm{N}=89)$} \\
\hline 1. Null ( 20 orthogonal factors) & 190 & 1031.95 & .37 & .30 & --- & --- \\
\hline 2. One factor & 170 & 664.64 & .52 & .41 & .41 & .43 \\
\hline 3. Five factors & 160 & 253.53 & .78 & .72 & .89 & .89 \\
\hline \multicolumn{7}{|l|}{ Company E Employees ( $N=97)$} \\
\hline 1. Null ( 20 orthogonal factors) & 190 & 1202.04 & .36 & .29 & --- & --- \\
\hline 2. One factor & 170 & 774.69 & .52 & .41 & .40 & .41 \\
\hline 3. Five factors & 160 & 270.85 & .80 & .74 & .89 & .90 \\
\hline
\end{tabular}

Note: $\mathrm{GFI}=$ goodness-of-fit index; $\mathrm{AGFI}=$ adjusted goodness-of-fit index: $\mathrm{CFI}=$ comparative fit index (Bentler, 1990); IFI = Incremental fit index (Bollen, 1988).

Model 3, the hypothesized model of five distinct factors, demonstrated significantly better fit indices than all the other models. Estimation of a single-factor model, in which the 20 items all loaded on the same construct, provided a very poor fit to the data. Although not shown in the table (in the interest of space), even the job and innovator, the job and team, the job and organization, and the job and career dimensions, exhibited better fit indices when loaded separately on their respective constructs. Although some of the companies had small sample sizes, we conducted a power analysis that demonstrated adequate power to reject a false 
model. Thus, these results support the distinction of five separate constructs as well as hypothesis 1.

\section{Stage 3: Construct Validity and Examination of Deficiency Error}

Construct validity and the examination of deficiency error were assessed by analyzing the ability of the RBPS to predict organizational outcomes above and beyond what is obtained via the company's own performance appraisal system. Five different analyses were conducted to demonstrate the additional contribution of the RBPS over traditional performance measures. In four of these analyses, we conducted hierarchical regressions to predict different indicators of "real" performance (i.e. 360-degree feedback, pay related performance measures, pay satisfaction, suggestion making activities, and hours worked), using traditional performance appraisal measures and the RBPS. In the fifth analysis, we looked at the correlations among the five factors of the RBPS and gainsharing satisfaction in three different companies. These five analyses lay the foundation for a nomological network for the RBPS.

360-degree feedback system. Company A provided us the opportunity to uniquely test our hypothesis 2 , which states that the RBPS is a better predictor of "real performance" than traditional appraisal methods. Company A employed a 360-degree type feedback system for evaluating employee performance. On a quarterly basis, supervisors were required to provide a performance report on all employees with whom they worked (either directly or indirectly) to a six member panel consisting of the firm's president and the five senior management vice presidents, one from each of the company's divisions. The supervisors based their overall evaluations on their own assessments of the individuals as well as assessments from self-reports. In addition, supervisors reviewed appraisals from customers and coworkers with whom the employees interacted. In turn, based on the supervisor's recommendations, the panel cast votes for those employees who had clearly gone above and beyond the call of duty in their performance during that quarter. Employees receiving the most votes (maximum of 6), were awarded a special status in the company, and various rewards were distributed accordingly (i.e. bonuses, newsletter recognition, plaques, etc).

This unique way of evaluating employees, although intensive and time consuming, provided a measure of performance that is considered by many researchers to be a very good way of capturing real performance (Gomez-Mejia, Balkin, \& Cardy, 1998). We hypothesized that since "real performance" most likely consisted of more than just the job facet, the RBPS should be a better predictor of this multi-rater evaluation than a traditional performance appraisal measure. 
We tested this hypothesis by conducting a hierarchical regression. The dependent variable was the vote of the panel (range varied on a 0-6 scale). We entered the firm's current performance appraisal rating in the first block of the regression analysis. In the second stage, we entered the cumulative score of the five components of the RBPS. Results indicated that the variance explained by the traditional performance appraisal method was .033 (n.s.). On the other hand, the RBPS added to the variance explained $\left(\Delta \mathrm{R}^{2}=.071, p \leq .05\right)$, indicating that the RBPS explains more variance in this unique measure of performance than does the traditional appraisal method. When the RBPS is entered first, the additional variance explained by traditional performance appraisal is $\Delta \mathrm{R}^{2}=.014, p=n . s$.).

Pay-related performance measures. Assuming that rewards systems are linked to "real performance," we investigated whether or not the RBPS was a better predictor of pay-related outcomes than traditional performance appraisal measures. In order to conduct the analysis for Company $A$, we used both current salary at the time of the data collection and the total incentive payment received by the employee for the current year (as of the data collection).

The RBPS added significantly to the variance explained in salary $(\underline{p}<.05)$, and incentives $(\underline{p}<.05)$. The traditional performance appraisal ratings did not predict either of the two dependent variables. Moreover, when the RBPS was entered first and then traditional measures second, the change in $R^{2}$ was non-significant in each case. These findings support our hypothesis that, the RBPS adds predictive power above what is obtained with the company's own traditional performance measure.

We conducted the same regression analysis for salary using data from company $B$, and we found similar results. The $\mathrm{R}^{2}$ explained by the traditional performance measure was .008 (n.s.). However, when the RBPS was added to the equation, the $\mathrm{R}^{2}$ increased by . $10(p \leq .01)$, indicating that the RBPS explained additional variance in salary beyond that accounted for by the traditional measure.

Pay satisfaction. We know from prior research that pay satisfaction is a function of 'real performance' and pay level (Ash, Lee \& Dreher, 1995; Dyer \& Therialut, 1976; Berger \& Schwab, 1980). In this paper, we argue that the RBPS is a better representation of "real" performance than traditional performance appraisal. Therefore, when controlling for pay (which should be related to pay satisfaction), we expect a stronger relationship between pay satisfaction and the RBPS than between pay satisfaction and the company's performance appraisal. Using data from Companies $A$ and $B$, we tested the relationship between pay, performance (measured both by performance appraisal and the RPBS), and pay satisfaction. 
Pay satisfaction was assessed by using Heneman \& Schwab's (1985) Pay Satisfaction Questionnaire. The four factors that comprise the scale were summed to obtain a total response per each employee. Reliabilities of the total scale were .93 for Company A and .93 for Company B. The results can be found in Table 3.

We ran regression equations with pay satisfaction as the dependent variable and both measures of performance (RBPS and performance appraisal) and pay as the independent variables. Both equations show that, as expected, pay is significantly related to pay satisfaction. However, in both companies, traditional performance appraisal is not related to pay satisfaction. In contrast, some of the components of the RBPS are significantly related to pay satisfaction in both firms. Thus, in support of hypothesis 2 , the RBPS adds predictive power above and beyond what is available with the firm's own performance appraisal instruments.

TABLE 3

Hierarchical Regression Analyses

\begin{tabular}{|c|c|c|c|c|c|c|c|c|}
\hline & \multicolumn{4}{|c|}{$\begin{array}{l}\text { Hierarchical Regression } \\
\text { Analysis Predicting Pay } \\
\text { Satisfaction }\end{array}$} & \multicolumn{4}{|c|}{$\begin{array}{l}\text { Hierarchical Regression } \\
\text { Analysis for Suggestion } \\
\text { Activity and Hours Worked }\end{array}$} \\
\hline & \multicolumn{2}{|c|}{ COMPANY A } & \multicolumn{2}{|c|}{ COMPANY B } & \multicolumn{2}{|c|}{$\begin{array}{l}\text { COMPANY B } \\
\text { Suggestion } \\
\text { Activity }\end{array}$} & \multicolumn{2}{|c|}{$\begin{array}{c}\text { Hours } \\
\text { Worked }\end{array}$} \\
\hline & Beta & $\mathrm{T}$ & Beta & $\mathrm{T}$ & Beta & $\mathrm{T}$ & Beta & $\mathrm{T}$ \\
\hline Salary & .17 & $2.07^{\star}$ & .17 & $1.97^{\star}$ & & & & \\
\hline Performance appraisal & -.03 & -.22 & .07 & .84 & .11 & 1.34 & .56 & .05 \\
\hline Career & .24 & 2.43 & .37 & $4.09 * \star *$ & -.20 & -2.31 & -.11 & -1.18 \\
\hline Innovator & -.09 & -.87 & -.06 & -.59 & .21 & $2.39^{\star *}$ & .15 & $1.73+$ \\
\hline Job & -.10 & -1.01 & -.24 & $-2.52^{\star}$ & .10 & 1.07 & -.07 & -.72 \\
\hline Organization & .12 & 1.12 & .07 & .65 & .06 & .64 & .25 & $2.55^{\star \star}$ \\
\hline Team & .18 & $1.69+$ & -.01 & -.11 & -.04 & -.41 & -.06 & -.52 \\
\hline$R^{2}$ & .13 & & .17 & & .09 & & .08 & \\
\hline $\mathrm{F}$ & $2.89^{\star *}$ & & $3.86^{\star \star *}$ & & $2.60^{*}$ & & $2.17^{*}$ & \\
\hline
\end{tabular}

Standardized regression coefficients are reported. 
Suggestion making activity and hours worked. In this analysis, we utilized two additional measures of performance (suggestion making activity and hours worked), using data from Company $\mathrm{B}$. We ran a regression analysis for each dependent variable, comparing the predictive power of the two measures of performance (company's performance appraisal and the RBPS).

The total number of suggestions submitted by employees for a one-year period of time (both formal and informal) ranged from 0 to 110, with a mean of 3.93 and a standard deviation of 10.57. A regression analysis was run with both the performance appraisal as well as all components of the RBPS included as independent variables. As also shown in Table 3, the results again indicate that the traditional performance appraisal is not significantly related to total number of suggestions, but the career (beta $=-.20, p \leq .05$ ) and innovator (beta $=.21, p \leq$ $.01)$ dimensions of the RBPS are significantly related to number of suggestions made. The total $\mathrm{R}^{2}$ for the equation is .09, $\mathrm{F}=2.60, p \leq .05$.

The average number of hours worked per week, for employees participating in the study, was 44.39 with a standard deviation of 8.17 (minimum of 20 and maximum of 75 ). The analysis predicting hours worked resulted in an $\mathrm{R}^{2}$ of .08 $(p \leq .05)$. Performance appraisal was not significant, but the innovator role (beta $=.15, \mathrm{p} \leq .10$ ) and the organization member role (beta $.25, \mathrm{p} \leq .01$ ) components of the RBPS were significant and positively predicted hours worked.

Relationship of RBPS with gainsharing satisfaction. The fifth analysis investigated the relationship between gainsharing satisfaction and the five roles of the RBPS. This analysis was conducted using data from three of the companies in the study (Pilot study firm and Companies $B$ \& D). Each firm had a gainsharing plan ${ }^{2}$ in effect for approximately one year at the time we collected the surveys.

All gainsharing plans were designed in a similar fashion. Each plan included a bonus based on increases in revenue and decreases in expenses, derived for each quarter. The bonus was paid out as a percentage of the individual's base pay (for details about gainsharing plan design see Graham-Moore \& Ross, 1990). In each case, the gainsharing plans were put into effect in order to elicit non-job role behaviors and the bonus was paid out when the entire work group achieved an increase in performance. The design of these plans suggests that job-based role behaviors are less likely to be related to gainsharing satisfaction than other roles. Thus, we

\footnotetext{
2 Gainsharing plans are group-based incentives that pay out a bonus when quarterly historical performance targets are exceeded. The bonus pool is divided, in most cases evenly, between the company and employees, with the employee portion paid out as a percentage of base pay. The quarterly bonus pool is based on the ability of the work group to exceed historical sales and/or reduce historical costs.
} 
expect that the non-job role components of the RBPS should be related to gainsharing satisfaction while the job role component should not be related.

The gainsharing satisfaction scale includes four items and uses a 1 to 5 Likert-type scale ranging from $1=$ very dissatisfied to $5=$ very satisfied. The items in the scale are: (1) how the gainsharing plan is administered, (2) the gainsharing plan, (3) the gainsharing formula, and (4) the way in which the gainsharing bonus is calculated. The coefficient alpha for the scale is above .90 for each firm.

The correlations for the three samples are included in Table 4. For all three companies, there was no significant correlation between performance in the job role and gainsharing satisfaction (correlations are .12, .06, and.03). However, for Company B there were significant correlations between gainsharing satisfaction and career performance (.34, $p \leq .001)$, innovator performance $(.20, p \leq .10)$, and organization performance $(.31, p \leq .05)$. In the pilot study company, significant correlations were found between gainsharing satisfaction and the innovator role $(.23, p \leq .05)$, the organization member role $(.42, p \leq .001)$, and the team member role (.26, $p \leq .05)$. In the third firm, Company $D$, the only significant correlation was between gainsharing satisfaction and the team member role $(.25, p \leq .10)$. Thus, the results show that the components of the RBPS do seem to be differentially related to gainsharing satisfaction, and in particular, in no company was gainsharing satisfaction related to the job role.

TABLE4

Correlations Between Gainsharing Satisfaction and Components of RBPS

\begin{tabular}{|l|c|c|c|c|c|}
\hline $\begin{array}{l}\text { GAINSHARING } \\
\text { SATISFACTION }\end{array}$ & Career & Innovator & Job & Organization & Team \\
\hline Company B, $\mathrm{n}=93$ & $.34^{\star \star *}$ & $.20+$ & .12 & .31 & .12 \\
\hline Pilot study, $\mathrm{n}=81$ & .031 & .23 & .06 & $.42^{\star \star *}$ & $.26^{\star}$ \\
\hline Company $\mathrm{D}, \mathrm{n}=48$ & .12 & .16 & .03 & -.22 & $.25+$ \\
\hline
\end{tabular}

$$
{ }^{* * *} p \leq .001 \quad{ }^{* *} p \leq .01 \quad{ }^{*} p \leq .05 \quad+p \leq .10
$$


In summary, a number of analyses show that the RBPS adds explanatory power for understanding a number of components of "real" performance at work, beyond that of traditional performance measures. This pattern of evidence provides initial support for the predictive ability of the RBPS. In addition, these initial findings suggest that the RBPS reduces some of the deficiency error found in typical performance measures.

\section{DISCUSSION}

Applying role and identity theories to performance measurement offers a unique approach to expanding prior work on performance measurement. The concept that roles are important for understanding work has been with us for years; however, to date, its specific theoretical implications for performance measurement and its link with identity theory have not been explored. Clearly, many of the ideas that we synthesized here are not new; they have been discussed by authors and practitioners working in the fields of organization behavior and human resource management. By putting these fairly well-established pieces of theory together, the RBPS provides an original contribution to solving an important piece of the performance measurement puzzle.

The results of our study provide initial evidence that a role-based measure of performance is a promising tool for both researchers and practitioners. Although limited to five roles, our development of the RBPS addresses several weaknesses in performance measurement highlighted at the beginning of this article. First and most importantly, unlike typical techniques, the RBPS has a theoretical framework. Second, our performance measure is multidimensional rather than unidimensional, accounting for multiple roles employees may take on in the workplace. Third, because the RBPS accounts for multiple roles, it reduces some of the deficiency error associated with typical performance measures that only focus on the job role. Fourth, the RBPS has a broader, more generalizable application than traditional techniques, which have been job or organization-specific. As a result, the RBPS allows for comparisons among jobs and organizations.

The studies conducted for this research not only provide data to support the reliability and validity of the RBPS but also suggest that it has face validity. In fact, as a result of our analyses, at least one of the participating firms in this research altered its performance appraisal system to reflect the domain of the RBPS. Furthermore, the RBPS has demonstrated some useful diagnostic properties. Thus, in addition to promising to be a more generalizable measure of performance that could be used in many research studies, the scale has high potential usefulness for organizations. 
Implications for Research

Although a great deal of research has investigated job performance links with job attitudes, personality variables, and work values, findings have been disappointing. Perhaps these discouraging results are due to an inadequate measure of performance (Organ, 1988). For example, despite the plethora of studies, job satisfaction research has yet to demonstrate a consistent and significant relationship with employee performance. It is quite possible that more satisfied employees do not necessarily perform their job holder role differently but rather engage in career-focused, innovator, team-member, or organizational-member roles. This same logic also may apply to research on pay satisfaction, organizational commitment, or any other attitude-based work.

In fact, in the analysis of the relationship between gainsharing satisfaction and the RBPS, we found that satisfaction with gainsharing was not linked to specific job-based performance but was significantly related to other factors in the RBPS. In addition, attitudes toward the group incentive were not related to the firm's established measure of performance appraisal. If we had used only traditional, job-based performance outcomes, the relationship between gainsharing satisfaction and performance might not have been detected. This is only one example of the importance of including a measure of performance that taps multiple role-based dimensions.

Another advantage for research is the short length of the RBPS. Although this performance measure has only 20 items, our preliminary findings suggest that it is reliable and valid. Since it is relatively short and easy to complete, its face validity is enhanced, and organizations are more willing to allow researchers to include the RBPS in surveys and questionnaires as a measure of employee performance.

Implications for Practice

From a business perspective, the RBPS offers firms a user-friendly and face-valid method for evaluating employee performance. Furthermore, it is a concise measure, which makes it easy to implement. Our studies demonstrated that the RBPS has unique diagnostic abilities. For example, we found that the RBPS was able to diagnose a missing link between a firm's current reward system and its performance appraisal method. Company $\mathrm{C}$ was surprised to find that although management in this company had a goal of team work, the team dimension of the RBPS did not predict performance. A tour of the plant revealed that employees' jobs involved little, if any, teamwork. This observation was confirmed in focus groups with employees conducted after the survey. The RBPS results and the follow-up meetings raised a red flag for the company. 
In our studies, we also found that the correlations between the self-ratings and the managerial ratings were diagnostic for the participating firms. In several cases, low or negative correlations indicated ineffective communication between management and employees. These communication issues were confirmed by qualitative follow-up studies. Low correlations tend to indicate that the performance goals of employees and their supervisors are mismatched.

Given the current interest in 360-degree feedback systems as well as the face validity and ease of administration of the RBPS, this measure may be a practical alternative for companies seeking input from multiple respondents. Recently, Bozememan (1997: 314) suggested that "one potential direction for multi-source performance appraisal might be to recognize the role-related nature of performance ratings from various rater perspectives and use this characteristic as an w1wintage for individual performance assessment." Clearly, the RBPS provides an easy tool for applying this type of role-related analysis.

\section{Limitations}

Like all studies, this study has limitations. One deficiency is an incomplete nomological network. Exploring the validity of a new construct consists of demonstrating that the pattern of correlations with other measures of other constructs adheres to theoretical expectations (Campbell, Trapnell, Heine, Katz, Lavallee, \& Lehman, 1996). In our study, we only looked at the relationships of the dimensions of the RBPS with gainsharing satisfaction, the company's traditional performance appraisals, salary, incentives, and pay satisfaction. On the other hand, we were able to show that the RBPS significantly added to explained variance in a number of measures of performance. This finding was particularly evident in company $A$ in which we had access to very specific performance criteria against which to test the predictive ability of the RBPS. Additional analyses in this area will prove useful for further validation of this measure.

Another potential limitation is associated with the job holder component of the RBPS. As discussed when reviewing results of the pilot study, the customer service item did not load on its hypothesized factor. Despite this result, we maintained that item for subsequent testing as the lack of correlation appeared to be idiosyncratic to the particular company we surveyed. However, in our subsequent analyses, the only item that demonstrated a low coefficient alpha for reliability estimates was the jobholder component. Once again, this finding was related to the customer service item. Although all other reliability estimates for the job factor equaled or exceeded .71, it may be inappropriate to assume that customer service is a predictive item in all jobs. In fact, responsibilities related to customers might best be included as a separate (6th) role. Further research is required to resolve this issue and to further analyze this item's inclusion in the job role dimension of the RBPS. 
One methodological limitation is that we did not control for halo effect. We only used coefficient alphas to assess the reliabilities of the RBPS. Typically, in order to control for halo effect, researchers use inter-rater reliabilities (Austin \& Villanova, 1992). Due to a limitation in managerial time, we were unable to collect this information on the scale. Future research may benefit from the use of inter-rater reliabilities using the RBPS.

Another methodological issue is that we did not specifically test the link between a company's total compensation system and the RBPS. According to identity theory logic, we should be able to observe close ties between the five subscales of the RBPS and a firm's compensation system. As discussed at the beginning of this study, we did not set out to specifically test an organization's ability to successfully elicit a certain role via a particular compensation strategy. Rather, identity theory was used along with compensation policies as clues combined with recommendations of researchers in the field, to ascertain a limited number of roles. Future research needs to address this issue in more detail. In addition to studying differences in stated compensation strategies, such studies would benefit by examining actual salience vs. intended salience. The difference may be considerable, and it may help organizations understand why their compensation systems are or are not effective in encouraging the behaviors needed for their firm to succeed.

One further limitation of this research is that we only examined five roles. Clearly, we may have overlooked other roles that are acknowledged through a firm's non-monetary rewards system or recognized in other ways. For example, we do not know if different roles would be elicited when organizations offer employees such options as job sharing or flex-time. In addition, we did not account for other potential employee roles that involve managerial and informal leadership behaviors. Nonetheless, our preliminary framework for the RBPS, with only five roles, provides a good initial basis for future work in discovering additional roles related to work performance.

\section{Conclusion}

Although this is a preliminary study of the validity of the RBPS, we believe this research makes a substantive contribution to research on performance measurement. In addition to providing a theory grounded measurement tool, we offer a reliable and valid performance method for both researchers and practitioners. Our study involved six companies, ten different data sets, a variety of occupations, and different organizational contexts. We hope that the combination of high face validity and supportive initial research results will encourage continued use of the Role-Based Performance Scale and additional work on its validation. 


\section{REFERENCES}

Ash, R.A., Lee, Y.L., \& Dreher, G.F. (1995). Exploring the determinants of pay satisfaction using better mousetraps. Paper presented at the meeting of the American Psychological Association, Los Angeles, CA: August.

Austin, J.T., \& Villanova, P. (1992) The criterion problem: 1917 - 1992. Journal of Applied Psychology, $\underline{77(6)}, 836-874$.

Bateman, T.S., \& Organ, D.W. (1983). Job satisfaction and the good soldier: The relationship between affect and employee "citizenship." Academy of Management Journal, 24(4), 587-595.

Berger, C.L. \& Schwab, D.P. (1980). Pay incentives and pay satisfaction. Industrial Relations, 19: 206-211.

Bernardin, H. J., Kane, J. S., Ross, S., Spina, J.D., \& Johnson, D.L. 1995. Performance appraisal design, development, and implementation. In: Ferris, G.R., Rosen, S.D. \& Barnum, D.T. Handbook of Human Resource Management, Cambridge, Massachusetts: Blackwell Publishers, Inc., pp. 462-493.

Bommer, W.H., Johnson, J.L., Rich, G.A., Podsakoff, P.M., \& MacKenzie, S.B. (1995). On the interchange ability of objective and subjective measures of employee performance. Personnel Psychology, 48, 587-605.

Borman, W.C., \& Motowidlo, S.J. (1997). Task performance and contextual performance: The meaning for personnel selection research. Human Performance, 10(2), 99-109.

Borman, W.C., \& Motowidlo, S.J. (1993). Expanding the criterion domain to include elements of contextual performance. In N. Schmitt, W.C. Borman, and Assoc. (Eds.) Personnel Selection in Organizations, pp.71-98, San Francisco, CA: Jossey-Bass.

Bozeman, D.P. (1997). Interrater agreement in multi-source performance appraisal: a commentary. Journal of Organizational Behavior, 13) (August/ September): 313-316.

Brief, A.P., \& Motowidlo, S.J. (1986). Prosocial organizational behaviors. Academy of Management Review, 11(4), 710-725.

Burke, P.J. (1991). Identity process and social stress. American Sociological Review, $\underline{56}, 836-$ 849.

Callero, P.L., Howard, J.A., \& Piliavin, J.A. (1987). Helping behavior as role behavior: Disclosing social structure and history in the analysis of prosocial action. Social Psychology Quarterly, 50(3), 247-256.

Campbell, J.D., Trapnell, P.D., Heine, S.J., Katz, I.M., Lavallee, L.F., \& Lehman, D.R. (1996). Self-concept clarity: Measurement, personality correlates, and cultural boundaries, Journal of Personality and Social Psychology, 70(1), 141-156.

Campbell, J.P. (1990). Modeling the performance prediction problem in industrial and organizational psychology. In M.D. Dunnette and L.M. Hough (Eds.), $\underline{\text { Handbook of }}$ 
Industrial and Organizational Psychology, (Vol. 1, 2nd ed., pp 687-732), Palo Alto, CA: Consulting Psychologists Press

Campbell, J.P., McCloy, R.A., Oppler, S.H., \& Sager, CE (1993). A theory of performance. In N. Schmidt, W.C. Borman, \& Assoc. (Eds.), Personnel Selection in Organizations, pp 35-70, San Francisco, CA: Jossey-Bass.

Cardy, R. L. \& Dobbins, G. H. (1994). Performance Appraisal: Alternative Perspectives. Cincinnati, OH: South-Western Publishing Co.

Dyer, L. \& Theriault, R. (1976). The determinants of pay satisfaction. Journal of Applied Psychology, 61: 596-604.

Gerhart, B., Minkhoff, H.B., \& Olsen, R.N. (1995). Employee compensation, theory, practice, and evidence. Center for Advanced Human Resource Studies, Cornell University, Ithaca, NY: working paper 95-04.

Gomez-Mejia, L.R. \& Balkin, D.B. (1992). Compensation, organizational strategy, and firm performance. Cincinnati, Ohio: South-Western Publishing Co.

Gomez-Mejia, L.R., Balkin, D.B., \& Cardy, R.L. (1998). Managing human resources. Upper Saddle River, NJ: Prentice-Hall, Inc.

Graham-Moore, B.E. \& Ross, T.L. (1990). Productivity gainsharing: How employee incentive plans can improve business performance. Englewood Cliffs, NJ: Prentice-Hall.

Heneman, H.G., \& Schwab, D.P. (1985) Pay satisfaction: Its multidimensional nature and measurement. Journal of Psychology, 20, 129-141.

Ilgen, D.R., \& Hollenbeck, J.R. (1992). The structure of work: Job design and roles. In M.D. Dunnette and L.M. Hough (Eds.), Handbook of Industrial and Organizational Psychology, (Vol. 2, 2nd ed., pp 165-207), Palo Alto, CA: Consulting Psychologists Press.

Jackson, S.E., \& Schuler, R.S. (1995). Understanding human resource management in the context of organizations and their environments. Annual Review of Psychology, $\underline{46}, 237-$ 204.

Jöreskog, K. \& Sörbom, D. (1993). LISREL 8: Structural Equation Modeling with the SIMPLIS Command Language, Chicago, IL: Scientific Software International. Inc.

Katz, D., \& Kahn, R.L. (1978). The social psychology of organizations. New York, NY: Wiley.

Lawler, E.E. (1994). From job-based to competency-based organizations. Journal of Organizational Behavior, 15, 3-15.

Lawler, E.E. (1992). The Ultimate Advantage, San Francisco, CA: Jossey-Bass.

Lawler, E.E. (1986). High Involvement Management: Participative Strategies for Improving Organizational Performance, San Francisco, CA: Jossey-Bass. 
Lawler, E.E., Mohrman, S.A., \& Ledford, G.E. (1992). Employee Involvement and Total Quality Management: Practices and Results in Fortune 1000 Companies, San Francisco, CA: Jossey-Bass.

Ledford, G. (1991). Three cases of skill-based pay: An overview. Compensation and Benefits Review, March-April, 11-23.

Mansfield, R. S. (1996). Building competency models: Approaches for HR professionals. Human Resource Management 35(1), 7-18.

Mead, G.H. (1934). Mind, Self, \& Society: From the Stand-point of a Social Behaviorist, Chicago, IL: The University of Chicago Press.

Milkovich, G. M. \& Boudreau, J.W. (1997). Human Resource Management, eighth edition, Chicago, IL: Irwin.

Milkovich, G.M \& Newman, J.M. (1990). Compensation, $3^{\text {rd }}$ edition. Homewood, IL: Irwin.

Miner, F.J. (1986). Computer applications in career development planning. In D.T. Hall \& Assoc. (Eds.) Career Development in Organizations, pp 202-235, San Francisco, CA: JosseyBass.

Motowidlo, S.J., Borman, W.C., \& Schmit, M.J. (1997). A theory of individual differences in task and contextual performance. Human Performance, 10(2), 71-83.

Motowidlo, S.J. \& Van Scotter, J.R. (1994). Evidence that task performance should be distinguished from contextual performance. Journal of Applied Psychology, 79(4), 475-480.

Murphy, K. R. \& Cleveland, J. N. (1995). Understanding Performance Appraisal, Thousand Oaks, CA: Sage Publications.

Noe, R.A., Hollenbeck, J.R., Gerhart, B. \& Wright, P.M., (1994). Human Resource Management: Gaining a Competitive Advantage. Burr Ridge, Illinois: Irwin.

Oeser, O.A., \& Harary, F. (1964). A mathematical model for structural role theory, II. Human Relations, 17, 3-17.

Organ, D.W. (1988). A restatement of the satisfaction-performance Hypothesis. Journal of Management, 14(4), 547-557.

Schein, E.H. (1980). Organizational Psychology, $3^{\text {rd }}$ edition, Englewood Cliffs, NJ: Prentice-Hall, Inc.

Schein, E.H. (1970). The role innovator and his education. Technology Review, 72, 33-37.

Stevens, M. \& Campion, M. (1994).The knowledge, skill, and ability requirements for teamwork: Implications for human resources management. Journal of Management, 20(2), 503-530. 
Thoits, P.A. (1992). Identity structures and psychological well-being: Gender and marital status comparisons. Social Psychology Quarterly, 55, 236-256.

Thoits, P.A. (1991). On merging identity theory and stress research. Social Psychology Quarterly, 54, 101-112.

Turner, R.H. (1978). The role and the person. American Journal of Sociology, 84(1), 1-23.

Van Dyne, L, Cummings, L.L., \& Parks, J.M. (1995). Extra-role behaviors: In pursuit of construct and definitional clarity (A bridge over muddied waters). Research in Organizational Behavior, 17, 215-285.

Van Dyne, L. \& LePine, J. A. (1998). Helping and voice extra-role behaviors: Evidence of construct and predictive validity. Academy of Management Journal, 41(1), 108-119.

Van Maanen, J., \& Schein, E.H. (1979). Toward a theory of organizational socialization. In B. Staw (Ed.), Research in Organizational Behavior, Vol. 1, Greenwich, CN: JAI Press, Inc.

Welbourne, T. \& Cable, D. (1995). Group incentives and pay satisfaction: Understanding the relationship through an identity theory perspective. Human Relations, $\underline{48(6)}, 711-726$.

Welbourne, T.M. \& Gomez-Mejia, L.R. (1995). Gainsharing: A critical review and a future research agenda. Journal of Management, 21(3), 559-609. 


\section{APPENDIX A}

The Role-Based Performance Scale*

JOB (doing things specifically related to one's job description)

1. Quantity of work output.

2. Quality of work output.

3. Accuracy of work.

4. Customer service provided (internal and external).

CAREER (obtaining the necessary skills to progress through one's organization)

5. Obtaining personal career goals.

6. Developing skills needed for his/her future career.

7. Making progress in his/her career.

8. Seeking out career opportunities.

INNOVATOR (creativity and innovation in one's job and the organization as a whole)

9. Coming up with new ideas.

10. Working to implement new ideas.

11. Finding improved ways to do things.

12. Creating better processes and routines.

TEAM (working with coworkers and team members, toward success of the firm)

13. Working as part of a team or work group.

14. Seeking information from others in his/her work group.

15. Making sure his/her work group succeeds.

16. Responding to the needs of others in his/her work group.

ORGANIZATION (going above the call of duty in one's concern for the firm)

17. Doing things that helps others when it's not part of his/her job.

18. Working for the overall good of the company."

19. Doing things to promote the company.

20. Helping so that the company is a good place to be.

* Use of this scale requires written permission from the first author of this paper. Copyright, 1996.

** "The company" was replaced with the name of the firm being studied. The response format was a 1 to 5 Likert-type scale, with 1=Needs much improvement, 2=Needs some improvement, 3=Satisfactory, 4=Good, and 5=Excellent. 